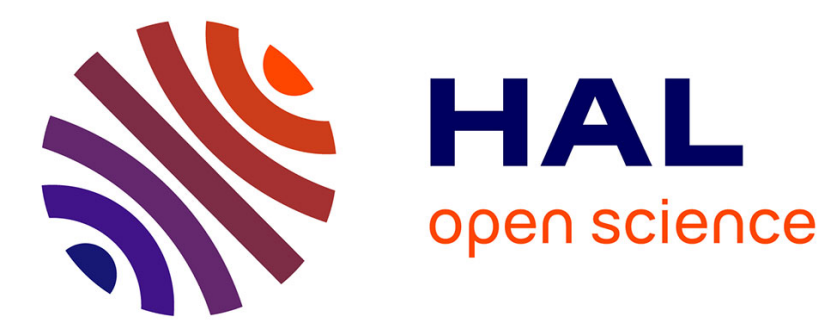

\title{
Process-Based Analysis of Digitally Transforming Skills
}

\author{
Ildikó Szabó, Katalin Ternai
}

\section{To cite this version:}

Ildikó Szabó, Katalin Ternai. Process-Based Analysis of Digitally Transforming Skills. 11th International Conference on Research and Practical Issues of Enterprise Information Systems (CONFENIS), Oct 2017, Shanghai, China. pp.104-115, 10.1007/978-3-319-94845-4_10 . hal-01888635

\section{HAL Id: hal-01888635 \\ https://hal.inria.fr/hal-01888635}

Submitted on 5 Oct 2018

HAL is a multi-disciplinary open access archive for the deposit and dissemination of scientific research documents, whether they are published or not. The documents may come from teaching and research institutions in France or abroad, or from public or private research centers.
L'archive ouverte pluridisciplinaire HAL, est destinée au dépôt et à la diffusion de documents scientifiques de niveau recherche, publiés ou non, émanant des établissements d'enseignement et de recherche français ou étrangers, des laboratoires publics ou privés. 


\title{
Process-based analysis of digitally transforming skills
}

\author{
Ildikó Szabó ${ }^{1}$ and Katalin Ternai ${ }^{1}$ \\ ${ }^{2}$ Corvinus University of Budapest, Fővám tér 13-15., 1093 Budapest, Hungary \\ ildiko.szabo2@uni-corvinus.hu \\ katalin.ternai@uni-corvinus.hu
}

\begin{abstract}
In Industry 4.0 a lot of jobs will be replaced by machines due to the technological revolution. Digital transformation entails new skills required to possess by people. This paper presents a solution to create data warehouse to assess future job skills based on the actual industrial business processes. The solution collects time series data from job portals and transforms them into the data warehouse to analyse skill sets. The structure of the data warehouse and the algorithm of extracting data from job vacancies have been introduced.
\end{abstract}

Keywords: digital transformation, business process, process ontology, skilled workforce

\section{$1 \quad$ Introduction}

The essential goal of Industry 4.0 is to push the manufacturing sector to its next transformation - in order to become more competitive, need to embrace emerging technologies, such as advanced analytics and cyber-physical system-based approaches to improve the efficiency and productivity. The key benefits of Industry 4.0 are to make business processes faster, more efficient and more customer-centric, while at the same time going beyond automation and optimization and detect new business opportunities and models. The human and social dimension are general in Industry 4.0. Tasks and demand for employees may change, however, different skills will be required [1]. New prophecies speak about jobs will be replaced by machines due to this technological revolution. As we learned from the prior industrial revolutions, job roles are transformed into new ones which require new or improved competences to execute their related activities.

\subsection{Skill relevance of digitally transformed business processes}

OECD and CEDEFOP have been investigating skills of future work since many years. OECD report published in 2016 emphasized the importance of ICT foundation skills to get better jobs and high wages by jobseekers. Inequality in possessing these skills is experienced among different age groups. Young adults are more prepared for the digital economy than the older ones. Jobs requiring more intensive ICT entail needs for other skills like "a solid level of information processing skills as well as the ability 
to collaborate, share information, give presentations, provide advice, work autonomously, manage, influence and solve problems" and social skills [2]. CEDEFOP survey also states that "at least moderate-level ICT skills also require a strong level of complementary skills, such as foundation skills (literacy, numeracy), soft skills (planning and organization) and behavioral skills (communication and teamwork). Jobs requiring advanced ICT skills depend heavily on people being able to solve problems, learn, adapt, apply new methods and technologies as well as in-depth technical knowledge". Highly risked groups for having digital skill gap are women, older-aged and lower-educated workers. Professionals in high skill intensive jobs must update their skill to avoid this gap [3]. The research conducted by the Institute for the Future for the University of Phoenix Research Institute revealed ten new skills based on six key drivers of change: sense-making, transdisciplinary, novel and adaptive thinking, social intelligence, new media literacy, computational thinking, cognitive load management, design mindset, cross cultural competency and virtual collaboration [4]. Organizational culture in the environment as Industry 4.0 must be a facilitator of learning and create behaviors in jobs. This requires changes in management practices to provide an appropriate organizational climate. Managerial skills can be derived from these management approaches: making organizational structure more adaptive, knowledge oriented leadership, HR practices or the cut-off of traditional investment style [5].

\subsection{Approaches for analyzing skill needs}

The studies conducted from macro perspective emphasizes the importance of ICT and related hard/soft, transversal skills in the future. But the organizational perspective can discover new areas like managerial practices within a learning and innovative organizational climate. Nevertheless, the comprehensive studies highlight the role of information systems to continually monitor and predicate skill needs and the commitment of educational institutions to integrate them into their training curricula and programs [2][3].

Studies, projects, frameworks, information systems built on key indicators or data tables deal with the analysis of skill needs. The New Skill for New Jobs initiative "is intended to promote an improvement in skills forecasting and matching the supply of skills to the needs of the labor market through better cooperation between the worlds of work and education." [6] The New Skills Agenda for Europe determines action points to equip people with new skills, transferring information to facilitate their job seeking and to improve their life chance. It is planned to provide upskilling pathways for adults, review European Qualification Framework, strength the co-operation among education, employment and industry stakeholders, develop a new framework for strategic cooperation between stakeholder to bridge short and medium-term skill gap to support the sectoral strategy [7].

More and more governmental data and other relevant data sources are available on the Internet due to the Linked Open Data, Open Data and Open Government Initiative. Skills Panorama created by the European Commission and developing by Cedefop "is a central access point for data, information and intelligence on skill needs 
in occupations and sectors that provides a European perspective on trends in skill supply and demand and possible skill mismatches, while also giving access to national data and sources." Research studies are provided about employment and future skills per country, per industry, per occupation [8]. Skills related statistics are available on the Eurostat portal. Employment, labour market supply and demand can be queried based on time series data along different dimensions (industry, occupation etc.). [9] ESCO (European Skills/Competences, Qualifications and Occupations) connects these three pillars of labour market and classifies their concepts into a comprehensive, ontology structure which will be queried semantically a SPARQL interface, following the Linked Open Data initiative [10]. These data sources or analytical tools [8][9] applied mainly the macro perspective and not the organizational perspective, because skill or competence sets are not analysed per industry or per occupation. ESCO ensures the bridge to connect analytical results per occupation to the skills of these occupations. Time series data of these competence sets are required to detect patterns or trends in this context. Job vacancies posted on popular job portals can provide these time series data and the contextual information about industry, occupations/position, activities, region etc. as well. During this research, a data warehouse is building from these information to provide further analysis of skill sets to mix macro and organizational perspective as well. Section 2 presents the related theoretical background of this research. The structure of this data warehouse and the algorithm of extracting these data from job vacancies are introduced in Section 3. Its implementation and test run are showed in Section 4. Conclusions about future work are drawn in Section 5 .

\section{Theoretical background}

\subsection{Semantic business process modelling, Process ontology}

Ontologies as well as semantic web have key role in semantic business process management (SBPM) [11]. Truly the semantic web relies heavily on ontologies to structure data for comprehensive and transportable machine understanding. Ontologies are an integral part of semantic web in facilitating knowledge sharing and reuse. In the field of SBPM, ontologies can be utilized for knowledge representation, knowledge engineering, information modelling, database development and integration, information retrieval and extraction, knowledge management and mining, and agent-based system development. They are used to share technical and business information throughout an organization or even in extended or virtual enterprises. An ontology is used as a mechanism for expressing and sharing enterprise knowledge to support intelligent queries.

Among the wide spectrum of approaches top level, domain and task level ontologies can be distinguished.

- Top-level ontologies - are used to represent the building blocks for a particular domain. 
- Domain level ontologies - are used to represent vocabulary related to certain domains.

- Task level ontologies - are used to represent vocabulary related to certain tasks.

A top-level ontology consists of very general terms such as "object", "property", "relation" that are common across domains. These ontologies are the first step towards knowledge representation for any domain. Terms in the domain ontology are ranked "under" the terms in the upper ontology and stand in subclass relations. Zhou and Kuntz [12] have developed a top-level ontology for representing the fundamental terms of a company, i.e. product, organization, activity, actor, facility, method and value. The framework consists of generic entities for providing products and services using material flow, information flow, and cost flow. Gialelis et al. [13] presented an ontological model for applications and systems that participate in collaborative processes. They have proposed an architecture that combines web services, ontologies, and workflows for efficiently carrying out the integration process under a collaborative environment. Here the integration is carried out by describing the enterprise processes by means of workflows and by using web services as a channel of communication within an enterprise. They test case was a procurement process carried out by suppliers for ordering materials, spare parts, tools, etc.. Task level ontologies are used to model the entities performing their respective operations and support interaction and interoperability among them. Generally, these ontologies are implemented in the field of multi-agent systems to model the tasks of various agent systems. Merdan et al. [14] presented a knowledge-intensive multi-agent architecture that enabled ontology-based communication and cooperation among a set of autonomous and heterogeneous agents.

Several enterprise information models are present in literature that describe the structure and relationships of data and information elements within enterprise information systems, such as CIMOSA, MOSES, MISSION, FDM [14,15,16,17]. These models have been developed for intra-enterprise integration, while some generic ontology models have been proposed for enterprise integration such as TOronto Virtual Enterprise (TOVE), GRAI, GERAM, ARIS, Enterprise ontology, PSL, Electronic business using eXtensible Markup Language (ebXML), Business Process Modelling language (BPML), etc. [18,19].

The Enterprise Ontology was developed under the Enterprise project to provide a collection of terms and definitions relevant to business enterprises [20]. The Enterprise Ontology was developed as a generic model oriented towards business and organizations. TOVE has been developed to support enterprise integration and communication [21]. TOVE provides a generic and reusable ontology for modelling enterprises.

BPML represents a process definition language intended for expressing abstract and executable processes that address all aspects of enterprise business processes [22]. It provides an abstract execution model for collaborative and transactional business processes based on the concept of a transactional finite state machine. ebXML is a family of XML standards sponsored by OASIS and UN/CEFAT [23]. It enables enterprises to conduct business over the internet.

Ontologies, as general but formalized representation can be used for describing the concepts of a business process. According to our research, process ontologies have no 
precise definition in the academic literature. Some refer to it simply as a conceptual description framework of processes [24]. In this interpretation process ontologies are abstract and general. Contrary, task ontologies determine a smaller subset of the process space, the sequence of activities in a given process [25].

The process ontology is used to reconcile the heterogeneous semantics of process modeling constructs, i.e. meta-model semantics existing in different process modeling languages. It indicates that process ontology should include a set of meta-concepts that are able to describe the semantics of process models.

In this paper the concept of process ontologies is used, where ontology holds the structural information of processes. The solution of establish the links between process model elements and ontology concepts has been prepared in the methodology. The attempt is to provide an extension for the standard ontology definition in the form of an annotation scheme to enable ontologies to cover all the major aspects of business process definition. The approach is identified as a semi-automatic generation of BPM defined ontology.

The objective of ontology learning is "to generate domain ontologies from various kinds of resources by applying natural language processing and machine learning techniques" [26]. Statistical, rule-based or hybrid ontology learning technique are distinguished based on the technique to detect correlations. The pattern-based ontology learning technique is one of them [27]. Our solution is a pattern-based ontology learning in that process ontologies transformed from industrial business processes are used as patterns.

\section{Labour market data warehouse}

A job vacancy posted on a given job portal usually contain the following information:

Its link, position, permanent/part-time job type, region, salary, start date, company name and job descriptions. The descriptions describe the tasks, responsibilities, requirements for fulfilling the given job. These information can be structured into the following tables:

- Calendar based on the publishing date

- Region: Region_ID, Region_name (from the job vacancy), Region_country (from geographical database)

- Industry: Industry_ID (NACE, SIC code etc. from national databases ), Industry_name (name of the given classification level), Company name (from the job vacancy)

- Occupation: Occupation ID (ISCO code from ESCO based on the position name), Occupation name (from ESCO)

- Job role: Job role_ID and name (from the actual process ontologies stored in databases) 
- Skill: Skill_ID (unique ID), Skill name (from the actual process ontologies stored in databases and from ESCO)

Additional data sources are used to complement these information. Having created this structure different queries can be executed in this data warehouse. E.g. the distribution of skills related a given occupation per industry.

Fig. 1.

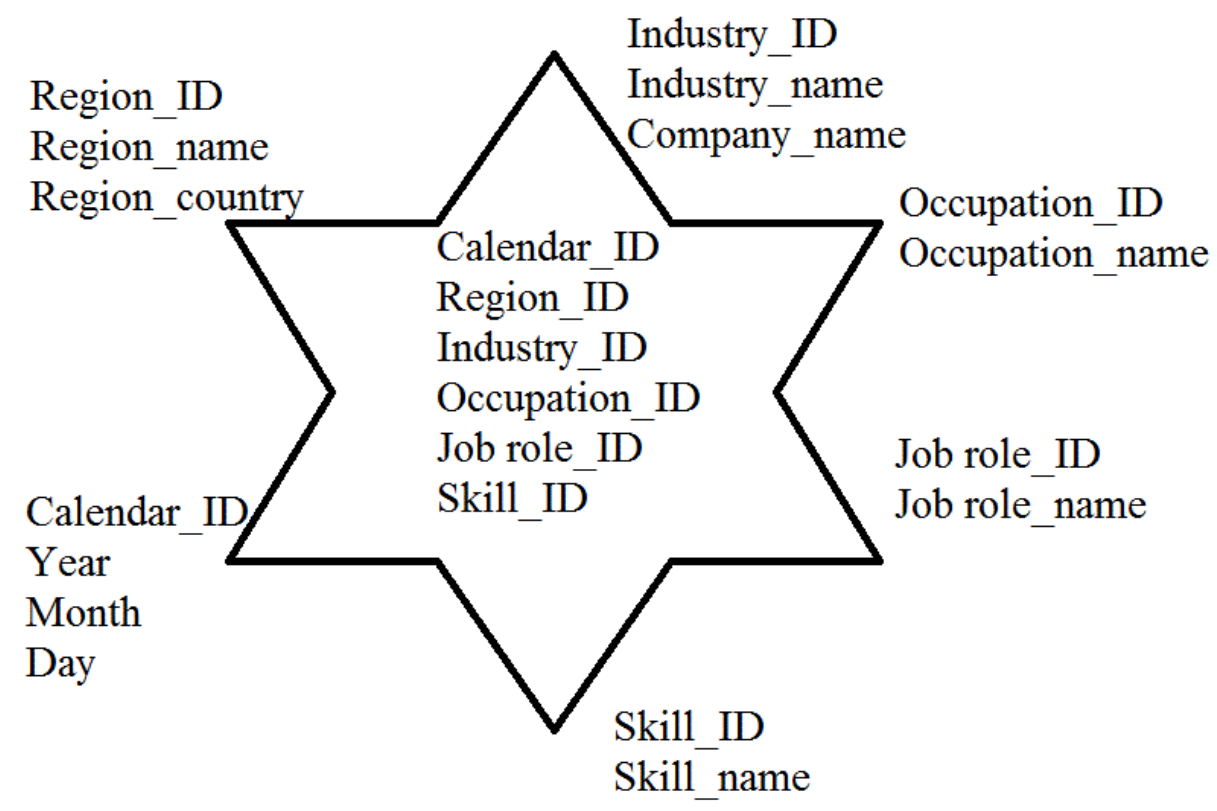

Fig 1. The structure of this data warehouse

The positions name, job roles and skills have to be extracted from job descriptions. But sometimes they are not so well-detailed. We need additional information in order to get these information.

Companies work along business processes whose activities must be executed by people filling the published positions. We assume that the activities mentioned in job vacancies are from these business processes.

Actual industrial business process models can reflect the organizational perspective and they can be created based on best practices. Skills to execute tasks are also determined by ESCO in these models. A database contains the process ontologies transformed from them (called as reference process ontologies).

We experienced that mainly tasks are presented in job descriptions and not competences. We use these process ontologies to identify the tasks and job roles in the job descriptions, because the relevant skills are identified based on them from the process ontology. The text mining algorithm is detailed in [28]. 


\section{$4 \quad$ Test}

By means of a concrete process from hospitality industry, a job portal called as JobSite from United Kingdom, we show the applicability of the method.

The first step is to determine the structure of a process model (task as process step, role as job role and required skill to execute this task by this role) and transform it into a process ontology.

In the use case the business process models were implemented by using BOC ADONIS modeling platform. [29] Our approach is principally transferable to other semi-formal modeling languages. There are several parameters that can be set or defined when modeling a business process in this tool, and in others as well. The shell of a business process can be easily formed with activities, decision points, parallelism or merging objects, logical gateways and events. The 'Supplying' business process model can be seen in Figure 1. 


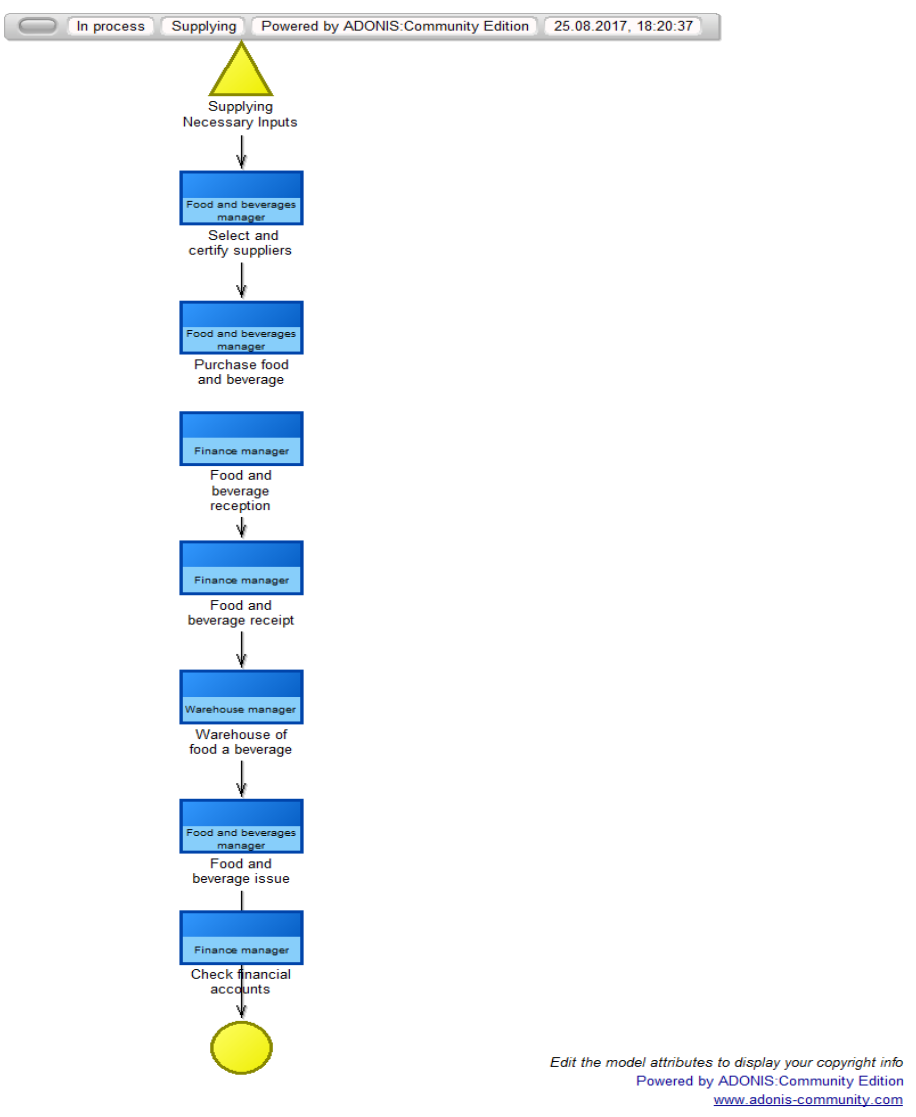

Fig. 2. The 'Supplying' process

The activities in the process:

\begin{tabular}{|l|l|}
\hline $\begin{array}{l}\text { Supplying Necessary Inputs } \\
\text { Process start }\end{array}$ & $\begin{array}{l}\text { Includes providing various kinds of goods } \\
\text { and materials for the hotel business as a } \\
\text { Description } \\
\text { influence These elements preferably } \\
\text { necessary goods and materials. } \\
\text { Consumables character of the material, or } \\
\text { the need for its continuous renewal, } \\
\text { conditioned by the continuity of the } \\
\text { business process. Given that certain types }\end{array}$ \\
\hline
\end{tabular}




\begin{tabular}{|c|c|}
\hline & $\begin{array}{l}\text { of goods and perishable foods subject, } \\
\text { there is no possibility of forming a stock } \\
\text { of goods of that kind, or the process } \\
\text { requires special conditions for its storage. }\end{array}$ \\
\hline \multicolumn{2}{|c|}{ Select and certify suppliers } \\
\hline Description & $\begin{array}{l}\text { selection of the best suppliers; } \\
\text { evaluates and selects suppliers based on } \\
\text { their ability to supply product in } \\
\text { accordance with the requirements of the } \\
\text { hotel. }\end{array}$ \\
\hline Responsible role & Food and beverages manager \\
\hline \multicolumn{2}{|c|}{ Purchase food and beverage } \\
\hline Description & $\begin{array}{l}\text { ordering food and drinks; } \\
\text { After the ordered food and drinks, with } \\
\text { his team performs a set of operations that } \\
\text { are related to the acquisition of foods and } \\
\text { drinks, such as delivery of merchandise, } \\
\text { unloading, the release of the packaging, } \\
\text { weighing and storage. Foodstuffs are } \\
\text { shipped in appropriate packaging which is } \\
\text { an important condition for hygienic and } \\
\text { health safety. }\end{array}$ \\
\hline Responsible role & Food and beverages manager \\
\hline \multicolumn{2}{|c|}{ Food and beverage receipt } \\
\hline Description & $\begin{array}{l}\text { quantitative and qualitative reception of } \\
\text { food and beverage; monitor financial } \\
\text { accounts;Receipt of goods from suppliers } \\
\text { accompanied by appropriate } \\
\text { documentation, conducted by the owner } \\
\text { of the process. The acknowledgment of } \\
\text { receipt of the goods is evidence that the } \\
\text { goods received are reviewed, tested, } \\
\text { compared with an order form, and } \\
\text { matches all elements in terms of quantity, } \\
\text { quality and price. }\end{array}$ \\
\hline Responsible role & Finance manager \\
\hline \multicolumn{2}{|c|}{ Food and beverage reception } \\
\hline Description & $\begin{array}{l}\text { quantitative and qualitative reception of } \\
\text { food and beverage; }\end{array}$ \\
\hline Responsible role & Finance manager \\
\hline
\end{tabular}




\begin{tabular}{|l|l|}
\hline Warehouse of food a beverage & $\begin{array}{l}\text { Warehouse of food a beverage; manage } \\
\text { stock rotation; }\end{array}$ \\
\hline Description & Warehouse manager \\
\hline Responsible role & $\begin{array}{l}\text { Food and beverage issue; } \\
\text { release of the good production process } \\
\text { and serving of food }\end{array}$ \\
\hline Food and beverage issue & Food and beverages manager \\
\hline Description & Monitor financial accounts \\
\hline Responsible role & Finance manager \\
\hline Check financial accounts &
\end{tabular}

To map conceptual models to ontology models we have used meta-modeling approach. Meta-models offer intuitive way of specifying modeling languages and are suitable for discussion with non-technical users. Meta-models are particularly convenient for the definition of conceptual models. In our approach, we establish the links between model elements and ontology concepts. As ontologies provide semantics, they can describe both semantics of the modeling language constructs as well as semantics of model instances. [29]

For the mapping the conceptual models to ontology models, the business process models are exported in the structure of ADONIS XML format. All objects from the business process model will be an 'instance' in the XML structure, the attributes have the tag 'attribute', while the connected objects (such as the performer, or the input/output data, which are stored in another model in the Adonis tool) have the tag 'interref'.

The „conceptual models - ontology models” converter maps the Adonis Business Process Modeling elements to the appropriate Ontology elements in meta-level. The model transformation aims at preserving the semantics of the business model. The general rule we follow is to express each ADONIS model element as a class in the ontology and its corresponding attributes as attributes of the class. This transformation is done by the means of XSLT script which performs the conversion. The converted OWL ontology in the structure of Protege/OWL XML format is imported into the editor of Protege 4.2.

To specify the semantics of ADONIS model elements through relations to ontology concepts, the ADONIS business model first must be represented within the ontology. Regarding the representation of the business model in the ontology, one can differentiate between a representation of ADONIS model language constructs and a representation of ADONIS model elements. ADONIS model language constructs such as "activity", as well as the control flow are created in the ontology as classes and properties. Subsequently, the ADONIS model elements can be represented through the instantiation of these classes and properties in the ontology. The linkage of the ontology and the ADONIS model element instances is accomplished by the usage of properties. These properties specify the semantics of an ADONIS model 
element through a relation to an ontology instance with formal semantics defined by the ontology. The final ontology can be seen in the Protégé editor in Figure 4.

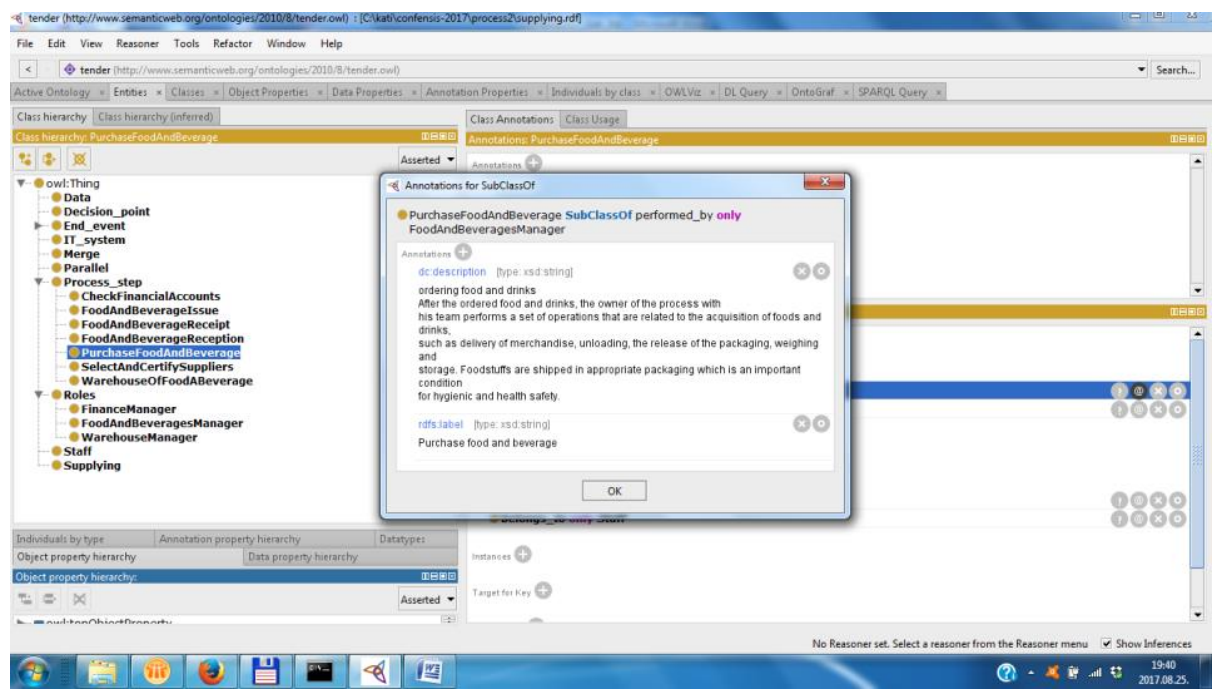

Fig. 3. The process ontology in Protege 5.0

The second step is to download job vacancies from the job portal and run the abovementioned algorithm to extract skills. A Java program was written to perform this step. 808 job description were processed by the algorithm. All process steps were identified, but the roles were called by different name in the job description. The accuracy of this algorithm must be tested by a confusion matrix in the future.

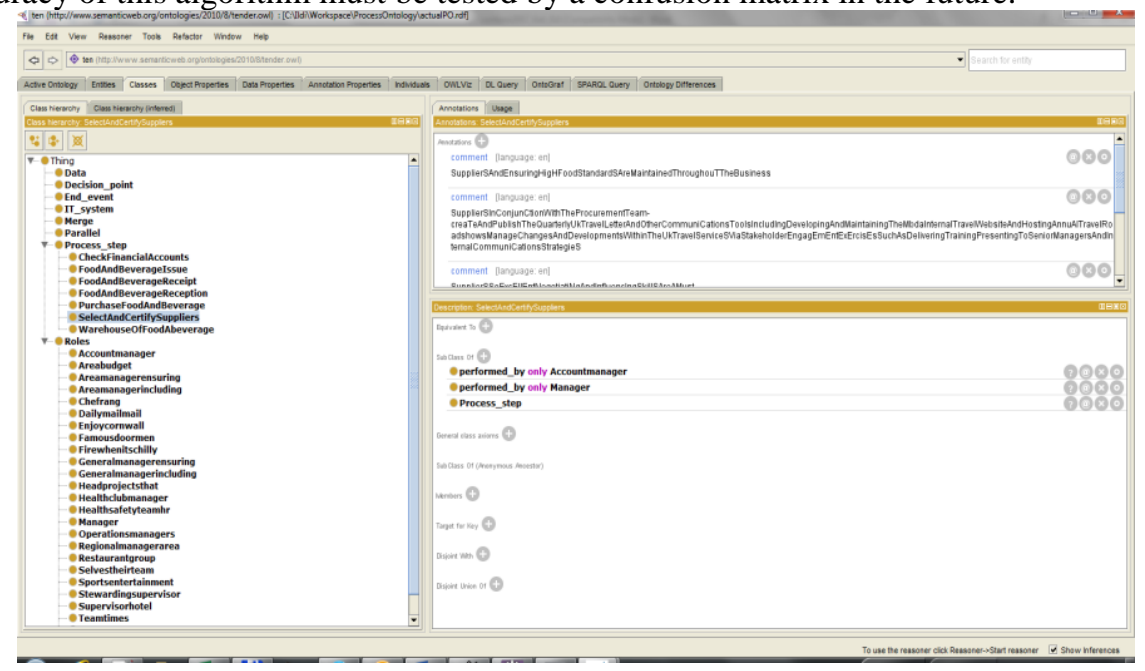

Fig. 4. Results of the extracting algorithm 


\section{$5 \quad$ Acknowledgment}

This research was supported by the project nr. EFOP-3.6.2-16-2017-00007, titled Aspects on the development of intelligent, sustainable and inclusive society: social, technological, innovation networks in employment and digital economy. The project has been supported by the European Union, co-financed by the European Social Fund and the budget of Hungary.

\section{Conclusions}

This paper presented a solution for collecting time series data from job portals and transforming them into a data warehouse to analyse skill sets in a deeply manner than in the case of Skills panorama, or the Eurostat databases. Some difficulties can emerge from data cleansing and identifying skill needs in job descriptions. Specific skills can be appeared in them which have to be extracted with an other algorithm. New scripts of functions are required to overcome these problems.

As future work we have to extend our algorithm with them. We can complement our solution with the results of Cedefop. OECD or the Institute for the Future. The skills mentioned in their report can be stored besides the process ontologies. It is worth to detect them in job descriptions to follow their history in the job vacancies: they are required by which occupation in which industry from when till when.

The occupational trends appeared in the Eurostat data can help to evaluate the future importance of collected skill sets, but this is the topic of an other connecting research.

\section{References}

1. D. Gorecky, M. Schmitt, M. Loskyll, D. Zuhlke, "Human-machine-interaction in the industry 4.0 era", 2014 12th IEEE International Conference on Industrial Informatics (INDIN), pp. 289-294, 2014.

2. OECD: Skill for a Digital World, http://www.oecd.org/els/emp/Skills-for-a-DigitalWorld.pdf, last accessed 2017/08/21

3. Briefing note - People, machines, robots and skills, http://www.cedefop.europa.eu/en/publications-and-resources/publications/9121, last accessed 2017/08/21.

4. Davies, A. et al.: Future work skills 2020. Institute for the Future for the University of Phoenix Research Center. (2011).

5. Shamim, S. et al.: Management approaches for Industry 4.0: A human resource management perspective. In: 2016 IEEE Congress on Evolutionary Computation (CEC). pp. 5309-5316 (2016).

6. : New Skills for New Jobs. Policy initiatives in the field of education: Short overview of the current situation in Europe. EACEA:] http://eacea.ec.europa.eu/education/eurydice/documents/thematic_reports/125EN.pdf, last accessed 2017/08/21. 
7. New Skills Agenda for Europe - Employment, Social Affairs \& Inclusion - European Commission, http://ec.europa.eu/social/main.jsp?catId=1223.

8. Skills Panorama | Cedefop, http://www.cedefop.europa.eu/hu/events-andprojects/projects/eu-skills-panorama, last accessed 2017/08/28

9. Eurostat - Data Explorer, http://appsso.eurostat.ec.europa.eu/nui/submitViewTableAction.do. , last accessed 2017/08/28

10. ESCO - ESCOpedia https://ec.europa.eu/esco/portal/escopedia/Main_Page.

11. Hepp, Martin and Roman, Dumitru, "An Ontology Framework for Semantic Business Process Management" (2007). Wirtschaftsinformatik Proceedings 2007. Paper 27.

12. Zhou, J. and Dieng-Kuntz, R. Manufacturing ontology analysis and design: towards excellent manufacturing. In Proceedings of the Second IEEE International Conference on Industrial informatics, INDIN '04, Berlin, Germany, 2004, pp. 39-45 (IEEE Computer Society).

13. Gialelis, J. V., Kalogeras, A. P., Alexakos, C. E., and Papadopoulos, G. Manufacturing collaborative process integration utilizing state of the art technologies. Proceedings of the IEEE International Symposium on Industrial electronics, ISIE 2005, Vol. 4, pp. 14291434.

14. Merdan, M., Kordic, V., Zoitl, A., and Lazinica, A. Knowledge-based multi-agent architecture. In Proceeding of the International Conference on Computational intelligence for modelling control and automation, and international conference on intelligent agents, web technologies and internet commerce (CIMCA-IAWTIC'06), Sydney, Australia, 2006 (IEEE Computer Society, Washington, USA).

15. Canavesio, M. M. and Martinez, E. Enterprise modelling of a project-oriented fractal company for SMEs networking. Computers in Ind., 2007, 58, 794-813.

16. Lin, H. K. and Harding, J. A. A manufacturing system engineering ontology model on the semantic web for inter-enterprise collaboration. Computers in Ind., 2007,58, 428-437.

17. Fox, M. S. and Gruninger, M. Enterprise modeling. AI Mag., 1998, 19, 109-121.

18. Schlenoff, C., Denno, P., Ivester, R., Libes, D., and Szykman, S. An analysis and approach to using existing ontological systems for applications in manufacturing. AI- EDAM, 2000, Vol. 14, pp. 257-270.

19. Schlenoff, C. and Uschold, M. Knowledge engineering and ontologies for autonomous systems: 2004 AAAI Spring Symposium. Robotics and Autonomous Systems, 2004, 49, $1-5$.

20. Goossenaerts, J. B. M. and Pelletier, C. Ontology and enterprise modelling. In Participative simulation environment for integral manufacturing enterprise renewal (Ed. Eijnatten), 2002, pp. 41-52 (TNO Arbeid, Amsterdam, The Netherlands).

21. Fadel, F., Fox, M. S., and Gruninger, M. A generic enterprise resource ontology. In Proceedings of the Third Workshop on Enabling technologies - infrastructures for collaborative enterprises, 1994, pp. 86-92.

22. Arkin, A. Business process modeling language (BPML), Working Draft 0.4, 2001, available online at http://www.bpmi.org/.

23. Waldt, D. and Drummond, R. EBXML: the global standard for electronic business, available online at http://www.ebxml.org/presentations/global_standard.htm.

24. Herborn, T., Wimmer, M.: Process ontologies facilitating interoperability in egovernment, A methodological framework. In: Workshop on Semantics for Business Process Management, the 3rd Semantic Web Conference. Montenegro (2006) 
25. Benjamins, V., R., Fensel, D.,Straatman, R.:Assumptions of problem-solving methods and their role in knowledge engineering. In: Poceedings ECAI-96, Wahlster, W. (Ed.), pages 408-412, (1996)

26. Haase, P., Völker, J.: Ontology Learning and Reasoning — Dealing with Uncertainty and Inconsistency. In: da Costa, P. et al. (eds.) Uncertainty Reasoning for the Semantic Web I. pp. 366-384 Springer Berlin / Heidelberg (2008).

27. Zhou, L.: Ontology learning: state of the art and open issues. Information Technology and Management. 8, 3, 241-252 (2007).

28. Szabó, I., Ternai, K.: Semantic Audit Application for Analyzing Business Processes. In: Tjoa, A.M. et al. (eds.) Research and Practical Issues of Enterprise Information Systems: 10th IFIP WG 8.9 Working Conference, CONFENIS 2016, Vienna, Austria, December 13-14, 2016, Proceedings. pp. 3-15 Springer International Publishing, Cham (2016).

29. BOC Group: Business Process Management with Adonis, http://www.bocgroup.com/products/adonis/, (2013)

30. Kramler, G., Murzek, M.: Business Process Model Transformation Issues, (2006) 